\title{
Leader's integrity and employee silence in healthcare organizations
}

\author{
Hakan Erkutlu \\ Faculty of Economics and Administrative Sciences, \\ Nevsehir Haci Bektas Veli Universitesi, Nevsehir, Turkey, and \\ Jamel Chafra
tel Management School of Applied Tech \\ Department of Tourism and Hotel Management School of Applied Technology and \\ Jamel Chafra
Management, Bilkent Universitesi, Ankara, Turkey
}

\begin{abstract}
Purpose - Drawing on the social exchange theory, the purpose of this paper is to examine the relationship between a leader's behavioral integrity and employee acquiescent silence. Specifically, the authors take a relational approach by introducing employee's relational identification as the mediator. The moderating role of employee political skill, in the relationship between behavioral integrity and employee acquiescent silence, is also considered.
\end{abstract}

Design/methodology/approach - The data of this study encompass 913 front-line nurses from 13 university hospitals in Turkey. Hierarchical multiple regression analysis was conducted to test the proposed model.

Findings - The results of this study support the negative effect of behavioral integrity on employee's acquiescent silence, as well as the mediating effect of employee's relational identification. Moreover, when the level of employee political skill is low, the relationship between behavioral integrity and acquiescent silence is strong, whereas the effect is weak when the level of political skill is high.

Practical implications - The findings of this study suggest that healthcare administrators' words and deeds should be consistent while interacting with their subordinates, as it leads to positive interpersonal relationship, which, in turn, lowers employee silence. Moreover, healthcare administrators should pay more attention to the buffering role of employee political skill for those subordinates with low relational identification and higher workplace silence.

Originality/value - This study contributes to the literature on workplace silence by revealing the relational mechanism between behavioral integrity and employee silence. This paper also offers a practical assistance to employees in the healthcare industry and their administrators interested in building trust and high-quality manager-employee relationship, as well as lowering workplace silence.

Keywords Behavioral integrity, Political skill, Relational identification, Employee silence

Paper type Research paper

\section{Introduction}

Employee silence refers to intentionally concealing information, ideas and opinions with relevance to improvements in organization (Van Dyne et al., 2003). Employees are perceived to be a main source of feedback to solve work-related issues (Morrison and Milliken, 2000). Thus, when members of the organization are silent, it is difficult to identify the pros and cons of different types of solutions. Moreover, employee silence reduces organizational commitment (Vakola and Bouradas, 2005), increases corruption (Ashforth and Anand, 2003), impedes innovation at workplace (Argyris and Schon, 1978) and causes absenteeism,
Received 18March 2018 Revised 11 May 2018 Accepted 24 May 2018 
LHS

32,3

turnover and other undesired behaviors (Carla, 1996). Individuals who intentionally restrict themselves from communication suffer from stress and physiological problems (Morrison and Milliken, 2000). Therefore, investigating the factors that are related with silence remains a fundamental issue in organization management.

Employee workplace silence is affected by leader's attributes, behaviors and attitudes (Detert and Burris, 2007). As a leader attribute, behavioral integrity is the perceived pattern of alignment between a leader's words and deeds (Simons et al., 2007). It is the extent to which employees perceive that their manager, or a group of managers, is/are keeping their promises and accurately representing themselves and their values in communications. Behavioral integrity greatly affects organizational commitment, citizenship behaviors, performance and intent to quit (Dineen et al., 2006). In this study, we focus on the process by which behavioral integrity shapes significant follower outcomes such as employee silence and relational identification with the leader. Yet, despite behavioral integrity's longstanding presence in the leadership literature, related research in the broad management and applied psychology literatures is still in its infancy. To date, no study, to our knowledge, has contributed to an understanding of how behavioral integrity relates to employees' workplace silence, despite the fact that leadership is one of the most influential predictors of employee silence (Detert and Burris, 2007); thus, the first goal of this study is to address this very untapped issue.

In addition, this study investigates political skill as the boundary condition for behavioral integrity, i.e. the relational identification relationship. Existing theories and research indicate that leadership behaviors and followers' individual difference variables, such as locus of control, proactive personality and political skill, significantly influence employee silence (Kish-Gephart et al., 2009; Premeaux and Bedeian, 2003). Prior researchers have emphasized that political skill is an important preventive source of undesirable outcomes such as workplace cynicism and workplace silence (Ferris et al., 2005). Yet, scholars have not considered the interactive effects of behavioral integrity and political skill on workplace silence; this relates to how leadership and organizational members are able to lower employee silence (Wu et al., 2012).

The present research is intended to contribute to the existing literature in several ways. First, our research seeks to fill the knowledge gap pertaining to the link between behavioral integrity and employee silence. Second, determining how relational identification lowers employees' workplace silence has received little empirical attention in relational identification-related literature (Liu et al., 2010). The present study uses the social exchange theory, as the core theoretical focus, and takes a step further to identify the mediating effect of relational identification on the behavioral integrity-employee silence link. The findings could advance our understanding of the processes by which behavioral integrity influences workplace silence. Finally, this study contributes to the literature by investigating how behavioral integrity lowers employees' silence via relational identification, which, in turn, accounts for the moderating effect of the political skill.

To test our theoretical model, we selected a context where employee silence is considered significant - the communication of frontline nurses in a hospital about issues affecting the safety of their patients. Patient safety has emerged as a major concern in healthcare organizations (Kanerva et al., 2017). High workload, interdependent interaction of multiple human (e.g. nurses, physicians, technicians and patients) and nonhuman (e.g. complex medical equipment) elements (Leape, 1994) of healthcare delivery in hospitals contribute to errors related to patient safety such as the administration of the wrong drug, surgery on the wrong side and accidental drug overdose. Proposed strategies for improving patient care underscore the need for hospitals to learn from, and prevent the recurrence of errors. In turn, 
this requires medical personnel in hospitals to candidly speak up with their opinions and concerns about unsafe conditions at work (Tangirala and Ramanujam, 2008). Such communication, especially from frontline nurses, is essential for analyzing the root causes of problems and implementing corrective actions. But, even as encouraging nurses to speak up is seen as an essential strategy for improving patient safety, the tendency of nurses to remain silent about unsafe conditions that they observe at work is seen as contributing to errors. For these reasons, the ongoing communication of frontline nurses about issues affecting the safety of their patients represents an appropriate context for studying employee silence. In addition, other general features of this context add to its relevance for this study. It has been suggested that studies of employee communication ought to be located in organizations where the work environment is "dynamic and new ideas facilitate continuous improvement" (Van Dyne et al., 2003). Hospitals with their rapidly changing technology and complex patient care procedures requiring multiple patient hand-offs meet this requirement. Moreover, given that employee silence is conceptualized as a work-focused communicative behavior of employees, it was particularly essential that the domain of our employee silence measures taps into a central component of the focal employees' work. Patient care constitutes the core element of nurses' daily work routine (Tangirala and Ramanujam, 2008). Finally, the highly hierarchical nature of healthcare sector where numerous professional groups (doctors, nurses, physiotherapists, laboratory personnel, etc.) interact to provide optimal patient care provides a suitable environment to study employee silence, because hierarchical organizational structures tend to reinforce workplace silence (Morrow et al., 2016). Hence, by investigating employee silence in the domain of patientrelated issues, we study communicative behaviors that also pertain to a critical and an important aspect of a nurse's work.

\section{Literature review and hypotheses}

\subsection{Behavioral integrity and employee acquiescent silence}

Employee silence is pervasive in modern organizations and has become a critical issue to organization management (Morrison and Milliken, 2000; Pinder and Harlos, 2001; Van Dyne et al., 2003). Employee silence refers to the intentional withholding of information, opinions, suggestions or concerns about potentially important organizational issues (Morrison and Milliken, 2000; Pinder and Harlos, 2001; Van Dyne et al., 2003). Employee silence often results from a conscious decision of employees to withhold seemingly important information and concerns about their work (Morrison and Milliken, 2000; Pinder and Harlos, 2001; Van Dyne et al., 2003). Though some scholars have pointed out that employee silence is not necessarily the antithesis of voice (Van Dyne et al., 2003), we take the same stance as Morrison (2014) by treating silence and voice as opposites in this study.

Scholars (Pinder and Harlos, 2001; Van Dyne et al., 2003) have argued that employee silence is a multidimensional construct. They have suggested that it can be classified into three categories according to motive: acquiescent silence (a disengaged behavior stimulated by resignation), defensive silence (a self-protective behavior stimulated by fear) and prosocial silence (an others-oriented behavior that is instigated by the cooperation motive). Acquiescent silence and defensive silence are often dysfunctional to organizations because they have the potential of interfering with organizational change (Morrison and Milliken, 2000) and of suppressing the improvement of organizational performance (Tangirala and Ramanujam, 2008; Van Dyne et al., 2003). In this study, we focused our attention on acquiescent silence because we were mainly interested in the types of employee silence that are of negative consequence to organizations. Prosocial silence, which is based on altruism 
LHS

32,3

or cooperative motives, aimed at benefiting others (Van Dyne et al., 2003), was not included in this study because it is often not harmful to organizations.

Acquiescence is neglecting existing choice and reluctance to seek out for any (Pinder and Harlos, 2001). Acquiescent silent individuals are reluctant to make a difference in their environment (Pinder and Harlos, 2001). According to Van Dyne et al. (2003), acquiescent silent individuals withhold work-related issues based on low self-efficacy to make change and disengagement from organizational issues. When superiors do not respond to delivered information from employees or when management discourages employees' participation in discussing organizational issues, employees perceive that speaking up is useless and does not make any change. Consequently, based on this perception, employees become acquiescent silent.

Previous research on behavioral integrity has posited strong theoretical links to trust. For example, Simons et al. (2007) examined the theoretical links between behavioral integrity and trust, with the key point being that a leader's high behavioral integrity may provide followers with a sense of certainty regarding the actions that the leader will take. With this sense of certainty, a follower is more likely to trust the leader. Simons et al. (2007) also provided some initial empirical evidence supporting the idea that behavioral integrity may lead to trust. Based on Simons' reasoning and initial evidence, Palanski and Yammarino (2009) proposed that leader behavioral integrity has a positive impact on follower trust in the leader.

Trust has substantial impact on information sharing and exchange (Dirks, 1999). Trust fosters communication and information sharing. If employees trust their managers and supervisors, they share their concerns without hesitation. In case of refraining from information sharing and speaking up, individuals are less likely to have organizational commitment (Tangirala and Ramanujam, 2008; Vakola and Bouradas, 2005).

In situations of reduced trust, individuals do not feel safe sharing work-related opinions because they fear from facing problems, such as punishment. Therefore, those individuals tend to avoid sharing their concerns due to fear or self-defense. Hence, there is positive relationship between trust and risk-taking behavior (Dirks and Ferrin, 2001). The more individuals have trust in their supervisors, the more they feel safe about supervisors' reaction for speaking up. Thus, employees with higher level of trust are more likely to express their opinions and concerns, whereas employees with lower level of trust are more likely to withhold their thoughts based on the fear and self-defense.

Moreover, trust in the leader is positively associated with the self-efficacy of employees (Yang and Mossholder, 2010). In other words, the higher the trust in the leader, the higher will be self-efficacy of individuals to make difference in organization. Therefore, we believe that employees with higher level of trust tend to have higher level of self-efficacy enabling them to share their concerns to make difference in their organization, whereas individuals with lower level of trust are more likely to have lower levels of self-efficacy to make change with their suggestions and remain acquiescently silent. Hence, we propose the following hypothesis:

H1. The perception of behavioral integrity is negatively related to employee's acquiescent silence.

\subsection{Behavioral integrity and relational identification}

Recent empirical research has shown that relational identification is an important identification outcome of leadership (Carmeli et al., 2011). Follower relational identification 
with leaders refers to the extent to which the subordinate's self-concept is defined by the relationship with the leader (Carmeli et al., 2011).

We propose that leader's behavioral integrity should affect follower relational identification because, by following up on promises, high behavioral integrity leaders send a clear message to followers that trust in the leaders is warranted. In addition, in consistently conveying the same values through words and actions, the leader clearly and unequivocally communicates what he or she truly values in work-related behavior, thus presenting the basis of personal and social identification of the follower with the leader.

The combination of direct and sincere communication of values and follow-up on promises and behavioral consequences of these value-statements will lead the follower to identify with the leader (Grojean et al., 2004). Therefore, it is expected that perceptions of leader behavioral integrity will increase employees' identification with the leader. Drawing on this literature, we expect a positive behavioral integrity-relational identification relationship. Thus, we present the following hypothesis:

H2. The perception of behavioral integrity is positively related to employee's relational identification.

\subsection{The mediating role of relational identification}

Identification processes have previously been proposed as a potential mediating mechanism in the leadership integrity/outcome relationship (Walumbwa et al., 2011). Relational identification represents the extent to which one defines oneself in terms of a given role-relationship (Sluss and Ashforth, 2007), in this case, the relationship with leader integrity. Relational identification seems to be particularly important because, especially for supervisory leaders, regular interaction with the leader is likely, and the relationship to the leader is psychologically closer than is the relationship to the organization. Therefore, relational identification should play a particularly important mediating role in the relationship between leader integrity and employee outcomes (Carmeli et al., 2011).

We propose that follower relational identification will mediate the relationships between leader integrity and follower silence. We know that followers who identify with their leader are more likely to engage in discretionary pro-organization behaviors (van Dick et al., 2006). Speaking up (voice) is one such behavior that may result from relational identification (Tangirala and Ramanujam, 2008). Voice is a behavior that involves proactively making suggestions to supervisors and management to enhance organizational efficiency by expressing concerns about current and potential problems or challenges (Morrison, 2014). Because voice is intended to aid organizational success, followers with higher relational identification are more likely to engage in voice behavior and less silence behaviors.

Leaders are known to influence follower behaviors and performance in part by shaping follower identities. Lord et al. (1999, p. 167) suggested that "leaders can profoundly influence subordinates' self-concepts, and thereby influence follower behavior and other social processes". We have argued that leader integrity will be associated with higher relational identification with the leader and that the latter should help to explain why followers of a leader with high integrity are more likely to perform well and to speak up to their leaders. Sluss and Ashforth (2007) argued that, with higher relational identification comes social attraction, interpersonal connection, a feeling of belongingness and openness to influence from the admired and respected identification target (the leader in this case). Followers of high integrity leader, with whom they identify, would want to meet that leader's performance expectations. Followers, who identify with their leader, should also feel more 
LHS

32,3

comfortable when speaking up to that leader about problems because, with identification, followers become more comfortable with the leader and have trust that speaking up is safe. Based on this perception, followers do not give up raising their work-related concerns and withhold those issues by becoming acquiescently silent. Thus, we present the following hypothesis:

H3. The negative relationship between behavioral integrity and employee's acquiescent silence is mediated by relational identification.

\subsection{The moderating role of political skill}

Political skill can be defined as the ability to effectively understand others at work, and to use such knowledge to influence others to act in ways that enhance one's personal and/or organizational goals. Politically skilled individuals are socially astute, and keenly aware of the need to deal differently with different situations and people (Jawahar et al., 2007).

Ferris et al. (2005) argued that politically skilled individuals enjoy a sense of personal security and self-confidence from previous experience in and efficacy within their work environments and the individuals with whom they interact. Such personal security and selfconfidence may contribute to politically skilled individuals exhibiting lower levels of workplace silence.

Thau et al. (2009) suggested that individuals have a need for predictability and are uncomfortable with uncertainty because the latter affects individuals' perceptions and feelings as well as threatens their sense of self. Therefore, individuals faced with uncertainty become worried about control in their lives and the potential outcomes that might result. Uncertainty has been associated with undesirable individual and organizational outcomes including stress, lower performance burnout and workplace silence. When uncertainty is high, individuals may focus on ways to reduce the uncertainty, deal with the discomfort and/or manage it effectively (Thau et al., 2009).

Political skill is one such variable that provides individuals with the ability to reduce uncertainty inherent in a workplace. Furthermore, it enables individuals to reduce the negative outcomes associated with uncertainty and enhance the associated positive outcomes. We propose that employees, high in political skill, are not likely to overrate the word-deed alignment of their managers (behavioral integrity) because they are able to control their environment and make it more predictable. However, for employees low in political skill, their leader's behavioral integrity is more important than that of employees with high political skill (Gandz and Murray, 1980) because they are unable to control their environment, and view it as more uncertain and prefer to work in a consistent leadership and stable workplace. Thus, low politically skilled individuals experience more uncertainty resulting in a stronger, negative behavioral integrity-workplace silence link. Based on these previous studies, we propose that political skill may play an important moderating role in the relationship between leader's behavioral integrity and employees' silence. Therefore, we suggest that political skill can provide an effective buffer against low levels of leader's integrity. Accordingly, we propose that the strength of the relationship between leader integrity and employee silence may vary among employees possessing different levels of political skill. Thus, the following hypothesis is proposed:

H4. Behavioral integrity influences employee silence through its relationship with relational identification, and the indirect effect will be stronger when the political skill is weak rather than when it is strong. 
Combining $H 1, H 2, H 3$ and $H 4$, we propose a moderated mediation model, as shown in Figure 1, to test the relationship between followers' perceptions of behavioral integrity and workplace silence; the model incorporates relational identification as a mediator and political skill as a moderator.

\section{Methods}

This study examined the relationship between leader's behavioral integrity and employee acquiescent silence, as well as the mediating (relational identification) and moderating (political skill) roles on that relationship. Figure 1 summarizes the theoretical model that guided this study.

\subsection{Participants}

This study was conducted in 13 university hospitals located in all seven geographical regions of Turkey and were randomly selected from the list of 65 university hospitals in the country (Ministry of Health of Turkey, 2018). Seven of them were state university hospitals, whereas the remaining six were private university hospitals.

We chose the healthcare industry because, starting from 2002, the healthcare system in Turkey underwent restructuring exercises to make it more innovative and cost efficient. As effective leadership is viewed as a key factor in attracting, motivating and maintaining employees in organizations undergoing change and transformation, we expected that the conditions in this industry provided an ideal test of the relationship between leader integrity and employee silence.

A cluster random-sampling method was used to select the sample. In this sampling method, first, all the university hospitals in Turkey were stratified into seven strata according to their geographic regions. Then, hospitals in each stratum were proportionally selected by a cluster random sampling; nurses working at the selected hospitals comprised the study sample.

The study was completed in August 2017-September 2017. A research team consisting of six doctoral students visited 13 university hospitals. During their first visit, post to receiving the approvals from the head doctors of the hospitals, they gave information about the aim of this study to the front-line nurses in their units and were told that the study was designed to collect information on the leader integrity and the employee silence levels in the healthcare

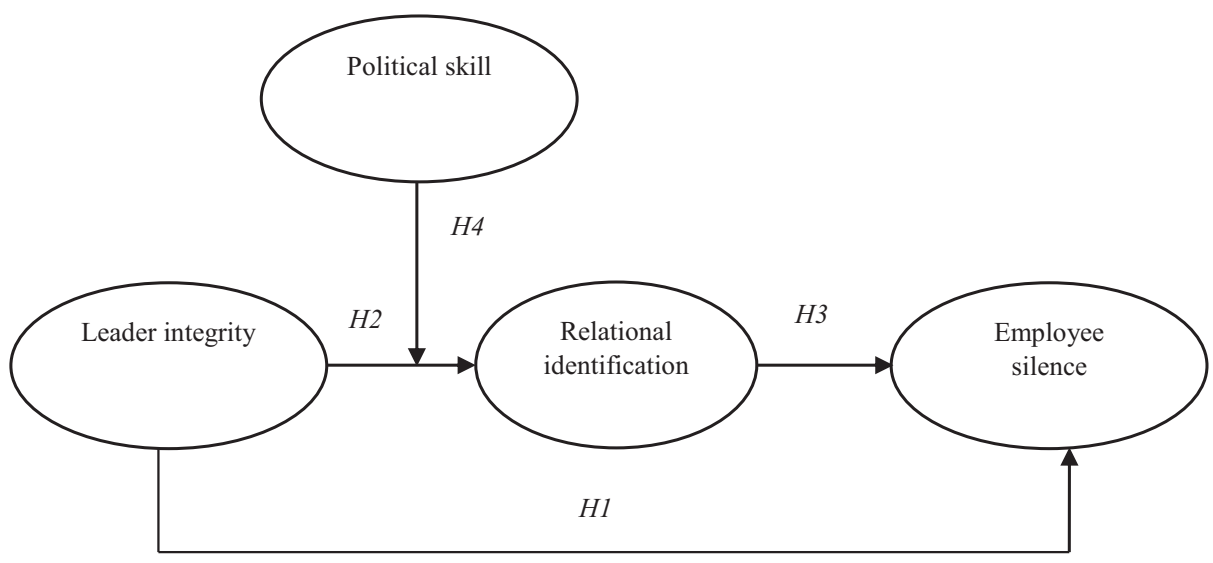

Figure 1. Hypothesized model of processes linking leader integrity and employee silence, moderated by political skill and mediated by relational identification 
LHS

32,3

workforce. They were given confidentially assurances and told that participation was voluntary. Nurses wishing to participate in this study were requested to send their names and departments by e-mail to the research team members.

During the second visit (two weeks later), all respondents were invited to a meeting room in their departments in which questionnaires were distributed, filled and immediately collected. A total of 1,300 front-line nurses participated in this study. Incomplete questionnaires reduced the sample size to 913 subjects resulting in a response rate of 70 per cent.

Participants comprising the final sample worked in one of the following seven departments: cardiology (26 per cent), neurology (23 per cent), accident and emergency (13 per cent), radiotherapy (12 per cent), gastroenterology (10 per cent), orthopedics ( 9 per cent) and nephrology (7 per cent). The average age of nurses was 27.93 years. Moreover, out of the 913 nurses, 79 per cent were female. Potential nonresponse bias was assessed by conducting a multivariate analysis of variance test on demographic variables such as gender, age and organizational tenure. No significant differences were found between respondents and nonrespondents, which indicates minimal, if any, non-response bias in the sample based on these factors.

\subsection{Measures}

3.2.1 Behavioral integrity. It was measured with eight-item behavioral integrity scale developed by Simons et al. (2007). Sample items include, "If my leader (the head nurse of the front-line nurse) promises something, it will happen" and "There is a match between (manager's) words and actions". All items are measured on a five-point scale ranging from (1) "strongly disagree" to (5) "strongly agree". The Cronbach's $\alpha$ for this measure turned out to be 0.91 .

3.2.2 Acquiescent silence. It was assessed by the five items scale adapted from Van Dyne et al.'s study (2003). A sample item is "I passively withhold ideas based on resignation". Respondents were asked to indicate the extent to which they agreed with the items on a fivepoint Likert-type scale ranging from 1 (strongly disagree) to 5 (strongly agree). The Cronbach's $\alpha$ for the scale was 0.90 .

3.2.3 Follower relational identification with the leader. It was measured using the tenitem measurement of identification with the leader developed and validated by Kark et al. (2003). The participants indicated the extent to which they agreed or disagreed with the ten statements about relational identification with the leader, with 1 indicating "strongly disagree" and 7 "strongly agree". Cronbach's alpha for this scale was 0.87 .

3.2.4 Political skill. It was measured with the 18-item political skill inventory developed by Ferris et al. (2005). Sample items include "I am good at getting people to like me" and "It is easy for me to develop rapport with most people”. A seven-point response format was used (strongly disagree to strongly agree). Cronbach alpha for this scale turned out to be 0.89 .

3.2.5 Control variables. The demographic factors, age and gender, found to be significantly related to employee silence (Wang and Hsieh, 2013), were controlled. Age was measured in years, whereas gender was measured as a dichotomous variable coded as 1 for male and 0 for female.

\section{Results}

Table I shows the descriptive statistics of the focal variables, including the means, standard deviations and correlations. Zero-order correlations were all in the expected direction. Leader integrity was positively related to employees' relational identification and negatively related to acquiescent silence ( $\beta=0.27, p<0.01$ and $\beta=-0.34, p<0.001$, respectively). 
Notably, the control variables (age and gender) were unrelated to the focal variables in the model. Following Becker's (2005) recommendations, we dropped those control variables from subsequent analysis. Becker recommended excluding control variables that are uncorrelated with the dependent variable to avoid reduced statistical power and increased Type II error (i.e. erroneously concluding that no relationship exists between the substantive variables and the dependent variable).

To test $H 1$, which states a negative relationship between leader integrity and employee silence and $H 2$, which states a positive relationship between leader integrity and employee's relational identification, we, respectively, regressed leader integrity on employee silence and relational identification $(\beta=-0.32, p<0.001 ; \beta=0.26, p<0.01$ ). We tested $H 3$, which states that relational identification mediates the relationship between leader integrity and employee silence according to Baron and Kenny's four conditions (Baron and Kenny, 1986), which are necessary to establish mediation. The analysis results show a significant effect of relational identification on acquiescent silence $(\beta=-0.27, p<0.01)$ and mediation effect $(\beta=0.07, p=\mathrm{ns} ; \beta=-0.24, p<0.01)$. The regression results for testing $H 1, H 2$ and $H 3$ are reported in Table II. Taken altogether, $H 1, H 2$ and $H 3$ were supported.

To test H4, which states a moderated mediation relationship between followers' perceptions of leader integrity and employee silence, incorporating relational identification as a mediator and political skill as a moderator, we used an approach by Muller et al. (2005). Results were interpreted using the bootstrapping method suggested by Edwards and Lambert (2007). H4 predicted that the indirect effect of relational identification for the leader integrity-employee silence relationships would be strengthened by low political skill and weakened by high political skill. To assess moderated mediation (Muller et al., 2005; Preacher et al., 2007), we examined three conditions:

\begin{tabular}{lccrrrrr}
\hline Variable & $M$ & SD & 1 & 2 & 3 & 4 & 5 \\
\hline 1. Age (year) & 27.93 & 2.69 & & & & & \\
2. Gender & 0.79 & 0.21 & 0.03 & & & & \\
3. Leader integrity & 3.23 & 0.69 & -0.06 & -0.03 & & & \\
4. Relational identification & 3.03 & 0.83 & 0.09 & 0.07 & $0.27^{* *}$ & & \\
5. Political skill & 3.66 & 0.91 & 0.06 & -0.06 & $-0.13^{*}$ & $0.21^{* * *}$ & \\
6. Acquiescent silence & 3.01 & 0.90 & -0.09 & -0.05 & $-0.34^{* * *}$ & $-0.30^{* * *}$ & $-0.32^{* * * *}$
\end{tabular}

Notes: ${ }^{*} p<0.05 ; * * p<0.01$ and ${ }^{* * *} p<0.001$

\section{$+2$}


LHS

32,3

\section{8}

(1) The independent variable must be related to the dependent variable, but there should be no interactive effect between the independent variable and the moderator on the dependent variable.

(2) The independent variable must be related to the mediator.

(3) The mediator $\times$ moderator product term significantly predicts the dependent variable; there must be a partial effect of the mediator on the outcome on average; there should be an overall treatment effect on the mediator.

For the first necessary condition, Model 1 in Table III showed that the effect of leader integrity on employee silence is significant $(\beta=-0.31, p<0.001)$. In addition, leader integrity $\times$ political skill (moderator) is not significant $(\beta=0.07$, ns). For the second necessary condition, Model 2 showed a significant effect of leader integrity on relational identification $(\beta=0.25, p<0.01)$. Therefore, Condition 2 has been met. For the third necessary condition, Model 3 showed a significant moderating effect of political skill through relational identification $(\beta=-0.13, p<0.05)$. There is a partial effect of relational identification on the outcome $(\beta=-0.24, p<0.01)$. Hence, the results based on the first three conditions indicate that political skill could moderate the mediation for leader integrity.

To test the indirect effects using bootstrapping, we constructed bias-corrected confidence intervals based on 5,000 random samples with replacement from the full sample. We adopted the Preacher et al.'s (2007) statistical significance test. Following Preacher et al.'s (2007) recommendation, we operationalized high, middle and low levels of political skill as one standard deviation above and below the mean score of the sample. Table IV presents the estimates, standard errors, $z$-statistics and significance values of the conditional indirect effects for employee silence across low and high levels of political skill.

Results show that the conditional indirect effects of employee silence were weaker and significant in the low and middle political skill condition (low-level effect $=0.049$, $* p<0.05$; middle level effect $=0.027, * p<0.05$ ), but were strong and nonsignificant in the high political skill condition (high-level effect $=0.007$, ns). Thus, $H 4$ was supported.

Table III.

Regression analyses for testing moderated mediation effects

\begin{tabular}{|c|c|c|c|c|c|}
\hline & \multicolumn{2}{|c|}{$\begin{array}{l}\text { Model } 1 \\
\text { Acquiescent silence }\end{array}$} & \multicolumn{2}{|c|}{$\begin{array}{c}\text { Model } 2 \\
\text { Relational identification }\end{array}$} & $\begin{array}{c}\text { Model } 3 \\
\text { Acquiescent silence }\end{array}$ \\
\hline & Beta & $t$ & Beta & $t$ & Beta $\quad t$ \\
\hline $\begin{array}{l}\text { Leader integrity (LI) } \\
R^{2} \\
\text { Political skill (PS) } \\
R^{2} \\
\mathrm{LI} \times \mathrm{PS} \\
R^{2} \\
\text { Relational identification (RI) } \\
R^{2} \\
\mathrm{PS} \times \mathrm{RI} \\
R^{2}\end{array}$ & $\begin{array}{r}-0.31 \text { *** } \\
0 \\
-0.30^{* * * *} \\
0.07 \\
\end{array}$ & $\begin{array}{c}-3.19^{* *} \\
-2.63^{* *} \\
0.05\end{array}$ & $\begin{array}{l}0.20 * * \\
0.03\end{array}$ & $\begin{array}{ll} & -2.60 * * \\
0.03 & \\
& 2.13^{* *} \\
0.02 & \\
& 0.02 \\
0.03 & \end{array}$ & 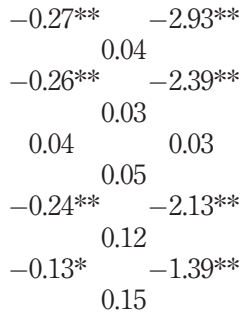 \\
\hline Notes: ${ }^{*} p<0.05 ;{ }^{* *} p<0.0$ & P & & & & \\
\hline
\end{tabular}




\section{Discussion}

We investigated and tested the negative relationship between leader's integrity and employee silence of university hospitals in Turkey. Data from our samples supported our initial hypotheses. Results showed that leader's integrity is negatively related to employee silence and positively associated with relational identification. Furthermore, relational identification provided an explanation of the relationship between behavioral integrity and employee silence. In addition, political skill effectively buffered the positive relationship between behavioral integrity and relational identification.

\subsection{Theoretical contribution}

This study linked two conventionally independent research areas, leader's integrity and employee silence, thereby opening up new avenues for enriching the development of each field. Dysfunctional leadership behavior such as narcissistic or abusive leadership or low behavioral integrity and employee silence is a widespread organizational phenomenon in the healthcare industry. Among the many negative consequences of low leader's integrity to an organization, employee silence is the most serious. Employees of leaders with low integrity perceive that their leaders are distrustful, lacking in empathy and sensitive to criticism (Dineen et al., 2006). Those leadership characteristics are clearly associated with difficulties in interpersonal relationships, which, in turn, lead to low trust in leader, leader-memberexchange quality, high counterproductive work behaviors and silence (Chiarini and Vagnoni, 2017; Meurs et al., 2013). This finding places leader's integrity as one important precedent to employee silence.

Another key contribution of this study rests on the role of relational identification as a mediator of the link between behavioral integrity and workplace silence. The findings contribute to relational identification literature by proposing leader's integrity as a new precedent of the relational identification. Traditionally, the negative effects of low relational identification have been limited to turnover intentions and performance (Chang et al., 2009). We have now expanded this to include the employee silence.

Given the call of broadening the criterion domain to include the interpersonal antecedents of employee silence (Tangirala and Ramanujam, 2008), this study adds to literature through the examination of the moderating role of political skill.

One noteworthy finding of this research is the moderated mediation model that applied the social exchange theory (Blau, 1964) to define the mediation path. This model provided a theoretical framework on how an independent variable (such as leader's integrity) may affect the dependent variable (employee silence) through the mediator (relational identification). As for the moderator, political skill moderated the mediating effect of relational identification on the indirect relationship between leader's integrity and employee silence. High levels of political skill lowered the mediating effect of relational identification.

\begin{tabular}{|c|c|c|c|c|c|}
\hline Moderator (political skill) & Conditional indirect effect & SE & $Z$ & $p$ & \\
\hline Level & & & & & Table IV. \\
\hline Low & $0.049 *$ & 0.03 & 2.33 & 0.03 & Moderated mediation \\
\hline Middle & $0.027 *$ & 0.03 & 2.19 & $\begin{array}{l}0.03 \\
0.06\end{array}$ & $\begin{array}{l}\text { rosults for leader } \\
\text { rested meation }\end{array}$ \\
\hline High & & & & 0.06 & integrity across \\
\hline \multicolumn{5}{|c|}{ Notes: $* p<0.05 ; * * p<0.01$ and $* * * p<0.001$} & levels of political skill \\
\hline
\end{tabular}




\section{LHS}

32,3

\subsection{Managerial implication and conclusion}

The growing complexity of the healthcare environment is placing considerable informationprocessing demands on healthcare administrators. More than ever, they are now compelled to go beyond formal communication mechanisms and rely on employees' voluntary contribution of ideas and information to the decision-making process. Hence, it has become important for healthcare administrators to understand the conditions that facilitate employee communication behaviors such as voice - employees' expression of challenging but constructive opinions, concerns or ideas about work-related issues (Chandrasiri, 2017; Tangirala and Ramanujam, 2008). This understanding can help administrators design interventions that aid the early detection of healthcare-related problems, opportunities and solutions and thereby facilitate organizational innovation and readiness for responding to unexpected situations.

The findings of this study are consistent with previous research results (Palanski and Yammarino, 2009; Simons et al., 2007) that leader's integrity causes significant organizational outcomes such as high levels of employee relational identification and lower employee silence. This study has important implications for healthcare management. The results highlight the importance of leader behavioral integrity as it is negatively related to employee silence. The implication is that the better the alignment between words and deeds, the greater credibility a leader has and the greater trust an employee will have in the leader. Healthcare managers have to be careful about behavioral integrity breaches, poor word-deed alignment and value misrepresentations because behavioral integrity affects trust at all levels. Thus, healthcare organizations, interested in creating trust in leaders and increasing organizational effectiveness, are well advised to consider leader behavioral integrity at all levels. They should ensure that both leaders and supervisors "walk the talk". It is particularly important, also, to look for signs of low behavioral integrity in recruiting and making promotions. Psychological tests by trained clinicians and interviews with a candidate's previous superiors and subordinates might flag a leader with low behavioral integrity. There is no doubt that the easiest way to deal with these managers is to avoid hiring them - or failing that - to refrain from giving them much power.

Relational identification is a unique construct that is distinct from organizational identification, and can provide novel insights into the role of employee social identification processes in understanding employee outcomes (Sluss and Ashforth, 2007). It makes theoretical sense that followers would be inclined to identify personally with a leader who cares about them, treats them fairly, is open to their input, sets ethical standards and aligns his or her words and deeds. In fact, our study shows that there is a significant positive relationship between leader's integrity and relational identification and that the latter has a significant negative effect on workplace silence. These findings demonstrate that relational identification should be considered as an important mediator in understanding leader integrity's effects on these positive follower outcomes. Identifying personally with high behavioral integrity leader is an important contributor to both follower outcomes, but especially to employee silence.

Given the goal of reducing the number of stresses in the workplace, acknowledging how stressful the state of low leader integrity is, is a starting point for the design of preventative interventions. For instance, if low behavioral integrity is recognized as a factor creating employee fear and strain for workplace silence, human resources experts might include supportive leadership styles such as transformational, servant, ethical or authentic leadership behaviors in curricula for management training programs. With respect to the goal of improved management of existing employee silence, the characterization of 
behavioral integrity, as a factor of trust in the leader, may benefit counseling and employee assistance initiatives. For instance, these programs may help employees recognize situations that lead to perceptions of low behavioral integrity as a contributing factor in their experience of silence. As such, employees may be able to learn how to cope with their feelings of the low leader integrity.

Our research showed that political skill lowers the negative effects of relational identification on employee silence. Managers should pay more attention to the buffering role of political skill especially for those employees with low relational identification and showing employee silence. Political skill is open to development and should be integrated into organizations' human resource development and performance management programs. Specifically, organizations should use developmental interventions aimed at increasing and sustaining overall political skill both in managers and in their employees. For example, relatively short (1-3 h) training interventions can be developed for overall political skill and tested for both online delivery and in traditional face-to-face workshops.

\subsection{Limitations and future research}

This study has potential limitations as well. First, our samples were only drawn from university hospitals in Turkey, thus external validity is a concern. Second limitation arises from the cross-sectional data, as no causal relationships can be established without longitudinal studies. Third, there would be socially desirable responding. Fourth, studies of leader behaviors and attitudes are confounded by socially desirable responding; the tendency of individuals to make themselves look good according to current cultural or organizational norms when answering researchers' questions. Finally, this study was based on self-report measures on leader's integrity and its outcomes. Using self-report data only, a potential for a method bias, is a clear limitation. Collecting data for the predictors and criterion variables from different sources would help to mitigate the potential for common method variance (Podsakoff et al., 2003).

Future research can be conducted to address the limitations pertaining to this study. We call for continuing empirical research on the relationship between leader's integrity and employee silence based on samples from hospitals that operate in other economies. For example, in cultures with high power distance (e.g. in China), employees often choose to remain silent about organizational problems and it is a virtue to respect and obey leaders as such, supervisors may determine appropriate behavior in line with behavior at higher organizational levels (Li and Sun, 2015). As consensus can only be reached by accumulating evidence from a more representative mix of samples, we offer the current findings as a basis for further research. It would be even more meaningful to conduct longitudinal studies to examine how the changes in leader's integrity affect employee silence.

\section{Reference}

Argyris, C. and Schon, D. (1978), Organizational Learning: A Theory of Action Approach, Addison Wesley, Reading, MA.

Ashforth, B.E. and Anand, V. (2003), "The normalization of corruption in organizations", Research in Organizational Behavior, Vol. 25 No. 1, pp. 1-52.

Baron, R.M. and Kenny, D.A. (1986), "The moderator-mediator variable distinction in social psychological research: conceptual, strategic, and statistical considerations", Journal of Personality and Social Psychology, Vol. 51 No. 6, pp. 1173-1182. 


\section{LHS}

32,3

Becker, T.E. (2005), "Potential problems in the statistical control of variables in organizational research: a qualitative analysis with recommendations", Organizational Research Methods, Vol. 8 No. 3, pp. 274-289.

Blau, P.M. (1964), Exchange and Power in Social Life, Transaction Publishers, New York, NY.

Carla, J. (1996), "Recreating the indifferent employee", HRM Magazine, pp. 76-81.

Carmeli, A., Atwater, L. and Levi, A. (2011), "How leadership enhances employees' knowledge sharing: the intervening roles of relational and organizational identification", The Journal of Technology Transfer, Vol. 36 No. 3, pp. 257-274.

Chandrasiri, S. (2017), "An ideal hospital: is leading a workforce engagement strategy the key to tackling bullying, harassment and discrimination in surgical practice?", Leadership in Health Services, Vol. 30 No. 3, pp. 263-271.

Chiarini, A. and Vagnoni, E. (2017), "TQM implementation for the healthcare sector: the relevance of leadership and possible causes of lack of leadership", Leadership in Health Services, Vol. 30 No. 3, pp. 210-216.

Detert, J.R. and Burris, E.R. (2007), “Leadership behavior and employee voice: is the door really open?”, Academy of Management Journal, Vol. 50 No. 4, pp. 869-884.

Dineen, B.R., Lewicki, R.J. and Tomlinson, E.C. (2006), "Supervisory guidance and behavioral integrity: relationships with employee citizenship and deviant behavior", Journal of Applied Psychology, Vol. 91 No. 3, pp. 622-635.

Dirks, K.T. and Ferrin, D.L. (2001), “The role of trust in organizational settings”, Organization Science, Vol. 12 No. 4, pp. 450-467.

Edwards, J.R. and Lambert, L.S. (2007), "Methods for integrating moderation and mediation: a general analytical framework using moderated path analysis", Psychological Methods, Vol. 12 No. 1, pp. 1-22.

Ferris, G.R., Treadway, D.C., Kolodinsky, R.W., Hochwarter, W.A., Kacmar, C.J., Douglas, C. and Frink, D.D. (2005), "Development and validation of the political skill inventory", Journal of Management, Vol. 31 No. 1, pp. 126-152.

Gandz, J. and Murray, V.V. (1980), "The experience of workplace politics”, Academy of Management Journal, Vol. 23 No. 2, pp. 237-251.

Grojean, M.W., Resick, C.J., Dickson, M.W. and Smith, D.B. (2004), "Leaders, values, and organizational climate: examining leadership strategies for establishing an organizational climate regarding ethics", Journal of Business Ethics, Vol. 55 No. 3, pp. 223-241.

Jawahar, I.M., Stone, T.H. and Kisamore, J.L. (2007), "Role conflict and burnout: the direct and moderating effects of political skill and perceived organizational support on burnout dimensions", International Journal of Stress Management, Vol. 14 No. 2, pp. 142-159.

Kanerva, A., Kivinen, T. and Lammintakanen, J. (2017), "Collaborating with nurse leaders to develop patient safety practices”, Leadership in Health Services, Vol. 30 No. 3, pp. 249-262.

Kish-Gephart, J.J., Detert, J.R., Treviño, L.K. and Edmondson, A.C. (2009), "Silenced by fear: the nature, sources, and consequences of fear at work", Research in Organizational Behavior, Vol. 29 No. 1, pp. 163-193.

Leape, L.L. (1994), "Error in medicine”, Journal of American Medical Association, Vol. 272 No. 23, pp. 1851-1857.

Li, Y. and Sun, J.M. (2015), “Traditional Chinese leadership and employee voice behavior: a cross-level examination”, The Leadership Quarterly, Vol. 26 No. 2, pp. 172-189.

Liu, W., Zhu, R. and Yang, Y. (2010), "I warn you because I like you: voice behavior, employee identifications, and transformational leadership”, The Leadership Quarterly, Vol. 21 No. 1, pp. 189-202.

Lord, R.G., Brown, D.J. and Freiberg, S.J. (1999), "Understanding the dynamics of leadership: the role of follower self-concepts in the leader/follower relationship", Organizational Behavior and Human Decision Processes, Vol. 78 No. 3, pp. 167-203. 
Meurs, J.A., Fox, S., Kessler, S.R. and Spector, P.E. (2013), "It's all about me: the role of narcissism in exacerbating the relationship between stressors and counterproductive work behavior", Work \& Stress, Vol. 27 No. 4, pp. 368-382.

Ministry of Health of Turkey (2018), Health Statistics Yearbook, Ministry of Health, Ankara.

Morrison, E.W. (2014), "Employee voice and silence", Annual Review of Organizational Psychology and Organizational Behavior, Vol. 1 No. 1, pp. 173-197.

Morrison, E.W. and Milliken, F.J. (2000), "Organizational silence: a barrier to change and development in a pluralistic world”, Academy of Management Review, Vol. 25 No. 4, pp. 706-725.

Morrow, K.J., Gustavson, A.M. and Jones, J. (2016), "Speaking up behaviours (safety voices) of healthcare workers: a metasynthesis of qualitative research studies", International Journal of Nursing Studies, Vol. 64 No. 1, pp. 42-51.

Muller, D., Judd, C.M. and Yzerbyt, V.Y. (2005), "When moderation is mediated and mediation is moderated", Journal of Personality and Social Psychology, Vol. 89 No. 6, pp. 852-863.

Palanski, M.E. and Yammarino, F.J. (2009), "Integrity and leadership: a multi-level conceptual framework", The Leadership Quarterly, Vol. 20 No. 3, pp. 405-420.

Pinder, C.C. and Harlos, K.P. (2001), "Employee silence: quiescence and acquiescence as response to perceived injustice", in Ferris, G.R. (Ed.), Research in Personnel and Human Resources Management, JAI Press, Greenwich, CT, pp. 331-369.

Podsakoff, P.M., MacKenzie, S.B., Lee, J.Y. and Podsakoff, N.P. (2003), "Common method biases in behavioral research: a critical review of the literature and recommended remedies", Journal of Applied Psychology, Vol. 88 No. 5, pp. 879-903.

Preacher, K.J., Rucker, D.D. and Hayes, A.F. (2007), "Addressing moderated mediation hypotheses: theory, methods, and prescriptions", Multivariate Behavioral Research, Vol. 42 No. 1, pp. 185-227.

Premeaux, S.F. and Bedeian, A.G. (2003), "Breaking the silence: the moderating effects of selfmonitoring in predicting speaking up in the workplace", Journal of Management Studies, Vol. 40 No. 6, pp. 1537-1562.

Simons, T., Friedman, R., Liu, L.A. and McLean Parks, J. (2007), "Racial differences in sensitivity to behavioral integrity: attitudinal consequences, in-group effects, and 'trickle down' among black and non-black employees", Journal of Applied Psychology, Vol. 92 No. 3, pp. 650-665.

Sluss, D.M. and Ashforth, B.E. (2007), "Relational identity and identification: defining ourselves through work relationships", Academy of Management Review, Vol. 32 No. 1, pp. 9-32.

Tangirala, S. and Ramanujam, R. (2008), "Employee silence on critical work issues: the cross-level effects of procedural justice climate", Personnel Psychology, Vol. 61 No. 1, pp. 37-68.

Thau, S., Bennett, R.J., Mitchell, M.S. and Marrs, M. (2009), "How management style moderates the relationship between abusive supervision and workplace deviance: an uncertainty management theory perspective", Organizational Behavior and Human Decision Processes, Vol. 108 No. 1, pp. 79-92.

Vakola, M. and Bouradas, D. (2005), "Antecedents and consequences of organisational silence: an empirical investigation", Employee Relations, Vol. 27 No. 5, pp. 441-458.

Van Dick, R., Grojean, M.W., Christ, O. and Wieseke, J. (2006), "Identity and the extra mile: Relationships between organizational identification and organizational citizenship behaviour", British Journal of Management, Vol. 17 No. 4, pp. 283-301.

Van Dyne, L., Ang, S. and Botero, I.C. (2003), "Conceptualizing employee silence and voice as multidimensional constructs", Journal of Management Studies, Vol. 40 No. 6, pp. 1359-1392.

Wang, Y.D. and Hsieh, H.H. (2013), "Organizational ethical climate, perceived organizational support, and employee silence: a cross-level investigation”, Human Relations, Vol. 66 No. 6, pp. 783-802.

Yang, J. and Mossholder, L.W. (2010), "Examining the effects of trust in leaders: a bases-and-foci approach", The Leadership Quarterly, Vol. 21 No. 1, pp. 50-63. 


\section{Further reading}

Dedahanov, A.T. and Rhee, J. (2015), "Examining the relationships among trust, silence and organizational commitment", Management Decision, Vol. 53 No. 8, pp. 1843-1857.

About the authors

Hakan Erkutlu is an Associate Professor at the Faculty of Economics and Administrative Sciences, Nevsehir University, Turkey. He received his $\mathrm{PhD}$ from the Gazi University, Turkey. His research interests include leadership, organizational conflicts, innovation and change. Hakan Erkutlu is the corresponding author and can be contacted at: erkutlu@nevsehir.edu.tr

Jamel Chafra is a Senior Lecturer at the School of Applied Technology and Management, Bilkent University, Turkey. His research interests include empowerment, group dynamics and organizational conflicts.

For instructions on how to order reprints of this article, please visit our website: www.emeraldgrouppublishing.com/licensing/reprints.htm Or contact us for further details: permissions@emeraldinsight.com 